\title{
Load-Bearing Capacity of the Footing Resting on a Reinforced Fly Ash Slope
}

\author{
Kulbir Singh Gill ${ }^{1}$, Anil Kumar Choudhary ${ }^{2}$, Jagada Nand Jha ${ }^{1}$ and Sanjay Kumar Shukla ${ }^{3}$ \\ 1. Civil Engineering Department, Guru Nanak Dev Engineering College, Ludhiana, Punjab, India \\ 2. Civil Engineering Department, National Institute of Technology, Jamshedpur, Jharkhand, India \\ 3. Discipline of Civil Engineering, School of Engineering, Edith Cowan University, Joondalup WA 6027, Australia
}

\begin{abstract}
In several parts of the world, disposal of waste materials such as fly ash is a great problem. Application of waste materials as structural fills in foundations is one of the best solutions to disposal problems, because wastes can be used in large volumes in such applications. There may be difficulty due to poor load-bearing capacity of fly ash, especially when footing rests on the top of the fly ash fill slope. Inclusion of polymeric reinforcements as horizontal sheets within the fill may be one of the most viable solutions to improving the load-bearing capacity of reinforced fly ash slope, and it is particularly important for the situations where foundations need to be located either on the top of a slope or on slope itself. The present work is aimed at investigating the efficacy of a single layer of reinforcement in improving the load-bearing capacity when it gets incorporated within the body of a model fly ash embankment slope. An increase in load bearing capacity due to the incorporation of reinforcement in the model slope was found by conducting laboratory tests. Experimental results were compared by numerical values obtained using software GEO5 and PLAXIS.
\end{abstract}

Key words: Reinforced fly ash slope, polymeric reinforcement, load bearing capacity, numerical analysis.

\section{Introduction}

Use of geosynthetic reinforcements to improve load-bearing capacity of foundation of different materials has been extensively reported by researchers. These investigations have demonstrated that ultimate bearing capacity and settlement characteristics of the foundation can be improved by the inclusion of reinforcements within the foundation material. In reality, there are many situations where foundations need to be located either on the top of a slope or on the slope itself, for example, foundations of bridge abutments, foundations constructed on hill slopes, etc. When a footing is constructed on a sloping ground, the bearing capacity of the footing may be significantly reduced depending upon the location of the footing with respect to slope. The improvement of load-carrying capacity of such loaded slopes is

\footnotetext{
Corresponding author: Jagada Nand Jha, PhD, research field: geotechnical engineering. E-mail: jagadanand@gmail.com.
}

therefore one of the important aspects of geotechnical engineering practice because such structures are liable to be unsafe due to slope failure. One of the possible solutions to improve the bearing capacity would be to reinforce the sloped fill with the layers of geogrid. To design a footing on a reinforced sloped fill requires a thorough understanding of both the bearing capacity behaviour of the footing and mechanical behaviour of the reinforced slope. Limited studies on bearing capacity behaviour of strip footings on a reinforced slope have been reported in the literature [1-7]. For the first time, Shukla et al. [8] presented a comprehensive overview of geosynthetic-reinforced slopes, including suitability of geosynthetics, modes of failure, methods of slope stability analysis and design, model studies, and typical slope stabilization methods and some specific recommendations. The decreasing availability of good construction sites has led to the increased use of low lying areas filled up with industrial wastes whose bearing capacity is low. Many times the industrial wastes (fly ash, blast furnace slag, etc.) often 
termed as man-made soils, if available locally and found suitable can reduce the construction cost significantly apart from encouraging the sustainable development and reducing the environmental problems. In several parts of the world, disposal of waste materials like fly ash is a great problem and requires a large land area. Acquiring open lands for disposal in developing countries like India is difficult due to small land-to-population ratio. In the areas of thermal power plants as well as in near-by areas, fly ash fill can be used to elevate the foundation level of footings in low-lying areas. Fly ash when used as structural fills or as embankments offers several advantages over borrow soils. It is light in weight, exerts low pressure on subgrade as a fill material and a well compacted embankment made of fly ash would exert only $50 \%$ of the pressure on a soft subgrade as a fill of equivalent height using coarse granular material and again the compaction curve of fly ash is relatively flat, thus implying that construction is less sensitive to compaction-moisture content than that of the fine grained soils commonly used as structural fill [9]. Fly ash being non-plastic will also solve the problem of dimensional instability as exhibited by plastic soils. Further properties of fly ash from a given source are likely to be more consistent as compared to the soil from natural borrow areas. There may be difficulty due to poor load-bearing capacity of fly ash, especially when footings are rested on the top of the fly ash fill slope. Inclusion of polymeric reinforcements as horizontal sheets within the fill may be one of the most viable solutions to improving the load-bearing capacity of reinforced fly ash slope. Studies on bearing capacity of shallow foundations on a level and plain fly ash ground have been reported in literature by several authors but limited studies on load carrying capacity behavior of footing resting on a reinforced fly ash slopes are available in the literature [9-11]. The bearing capacity determination technique is an important part of any correct design of footings on reinforced slope. In recent years numerical analyses such as finite difference and or finite element analyses have become popular in design practice. However despite many attempts, no obvious method for determination of ultimate bearing capacity of strip footing on reinforced slope is available and therefore much investigation still remains to be carried out. In view of limited information available on this aspect in the literature, the aim of present investigation is to find out the efficacy of a single layer of reinforcement in improving the load-bearing capacity when it gets incorporated within the body of a model fly ash embankment slope. The study aimed to find out both qualitative and quantitative relationship between load carrying capacity and optimum geometry of geosynthetic placement. An increase in load bearing capacity due to the incorporation of reinforcement in the model slope was found by conducting laboratory tests. These experimental results were compared by load bearing capacity values obtained numerically using software GEO5 and PLAXIS, assuming acceptable minimum factor of safety for the worst condition. Other factors as edge distance $\left(D_{e}\right)$, depth of embedment $(Z)$ and slope angle $(\beta)$ influencing the behavior of footings resting on the top of a slope, were also studied for un-reinforced and reinforced cases. The details of various parameters considered during the investigation and acceptable factor of safety are given in Table 1.

\section{Laboratory Model Tests}

Fly ash procured from electrostatic precipitators of TISCO (Tata Iron and Steel Company Limited), Jamshedpur, India was used throughout the investigation. As per particle size distribution, fly ash consists of $68 \%$ silt and $28 \%$ sand. Using standard proctor test, the maximum dry unit weight and the corresponding optimum moisture content (OMC) were found to be $9.34 \mathrm{kN} / \mathrm{m}^{3}$ and $48 \%$, respectively. The value of apparent cohesion $(c)$ and angle of internal friction $(\phi)$ were $20 \mathrm{kPa}$ and $14^{\circ}$, respectively. Commercially available polypropylene model geogrids 
Table 1 Variables of the investigation and acceptable factor of safety.

\begin{tabular}{|c|c|c|c|c|}
\hline \multicolumn{3}{|c|}{ Variables (Laboratory test and numerical analysis) } & \multicolumn{2}{|l|}{ Factor of safety [Datta (12)] } \\
\hline Type of test & Constant parameter & Variable parameter & Condition & $\begin{array}{l}\begin{array}{l}\text { Acceptable factor of } \\
\text { safety }\end{array} \\
\end{array}$ \\
\hline Unreinforced slope & $B=100 \mathrm{~mm}$ & $\begin{array}{l}D_{e} / B=1.0,2.0,3.0 \\
\beta=45^{\circ}, 60^{\circ}\end{array}$ & Static case (long term) & 1.5 \\
\hline \multirow{3}{*}{$\begin{array}{l}\text { Reinforced slope } \\
\text { single layer } \\
\left(L_{r}=7 B\right)\end{array}$} & \multirow{3}{*}{$\begin{array}{l}B=100 \mathrm{~mm} \\
N=1\end{array}$} & $\begin{array}{l}Z / B=0.25,0.50,0.75,1.0, \\
1.5,2.0,2.50,3.0\end{array}$ & $\begin{array}{l}\text { Seepage flow during monsoon } \\
\text { (short duration) }\end{array}$ & 1.3 \\
\hline & & $D_{e} / B=1.0,2.0,3.0$ & $\begin{array}{l}\text { Earthquake loading (very short } \\
\text { duration ) }\end{array}$ & 1.1 \\
\hline & & $\beta=45^{\circ}, 60^{\circ}$ & $\begin{array}{l}\text { Earthquake loading and seepage } \\
\text { flow simultaneously (rare) }\end{array}$ & 1.0 \\
\hline
\end{tabular}

(0.27 mm thick and $300 \mathrm{~mm}$ wide) having an average tensile strength $(E A)$ of $4.0 \mathrm{kN} / \mathrm{m}$ and tie-soil friction angle $\left(\phi_{\mu}\right)$ equal to $35^{\circ}$ were used as reinforcing elements. A series of plain strain model tests were conducted on unreinforced and reinforced fly ash model slopes by loading it with strip footing resting on the crest of slope to failure. The experimental set up and test procedure have been reported in detail by Choudhary et al. [9]. The geometry of the test configuration has been shown in Fig. 1 and in total three series of 54 model tests were performed.

\section{Numerical Approach}

A series of two dimensional finite element analysis (FEA) using PLAXIS version 8.0 software and GEO5 software based on the limit equilibrium theory were performed for numerical analysis on reinforced fly ash slope in order to verify the laboratory model test results. PLAXIS version 8.0 software allows automatic generation of 15 node triangle plane strain elements for the soil. The factor of safety (FOS) for the worst condition was taken from the value suggested by Datta [12] for four different critical cases based on stability analysis as given in Table 1. The FOS considered in the analysis for PLAXIS and GEO5 are 1.1 and 1.0, respectively. The parameters used for numerical analysis is depicted in Table 2. Figs. 2 and 3 show a typical deformed mesh and total displacement when the edge distance of the footing is equal to footing width $(B)$, slope angle $(\beta) 45^{\circ}$ and embedment depth $(Z)$ $0.75 B$, respectively whereas Fig. 4 shows a typical failure surface drawn for the same case using GEO5.

\section{Results and Discussion}

The improvement in load carrying capacity was described in terms of a non-dimensional factor called bearing capacity ratio (BCR), which is defined as ratio of load carrying capacity of footing with reinforced slope to the load carrying capacity of footing without reinforcement. The effect of embedment ratio $(Z / B)$ of single layer of geogrid reinforcement on BCR was studied by placing it within the fly ash fill at different depths from the top surface. Figs. 5 and 6 show the comparison of experimental and numerical value of BCR for strip footing against the normalized depth $(Z / B)$ at different footing location $\left(D_{e}\right)$ from the slope crest for the slope angles $(\beta)$ of $45^{\circ}$ and $60^{\circ}$ considered in the investigation. It is clear that improvement in bearing capacity of reinforced fly ash slopes not only depends upon the embedment depth of reinforcement layer but also on the edge distance for both the slope angles, and maximum value of BCR is obtained when the embedment ratio lies in the range of $0.75-1.0$ for almost all the cases considered in the laboratory model test. Numerical analysis shows similar trend of results which provide confidence in the reliability of the results obtained from the model tests. The maximum value of BCR as obtained from PLAXIS occurs at $\mathrm{Z} / \mathrm{B}=0.5-0.75$ and for GEO5 it is at 0.75-1.0. Therefore maximum range of improvement occurs when embedment depth ratio $(Z / B)$ ranges from 0.5-1.0. In this range, the plastic failure zone of fly ash slope is intercepted by the geogrid layer and the stress distribution is extended much below it. This in effect 


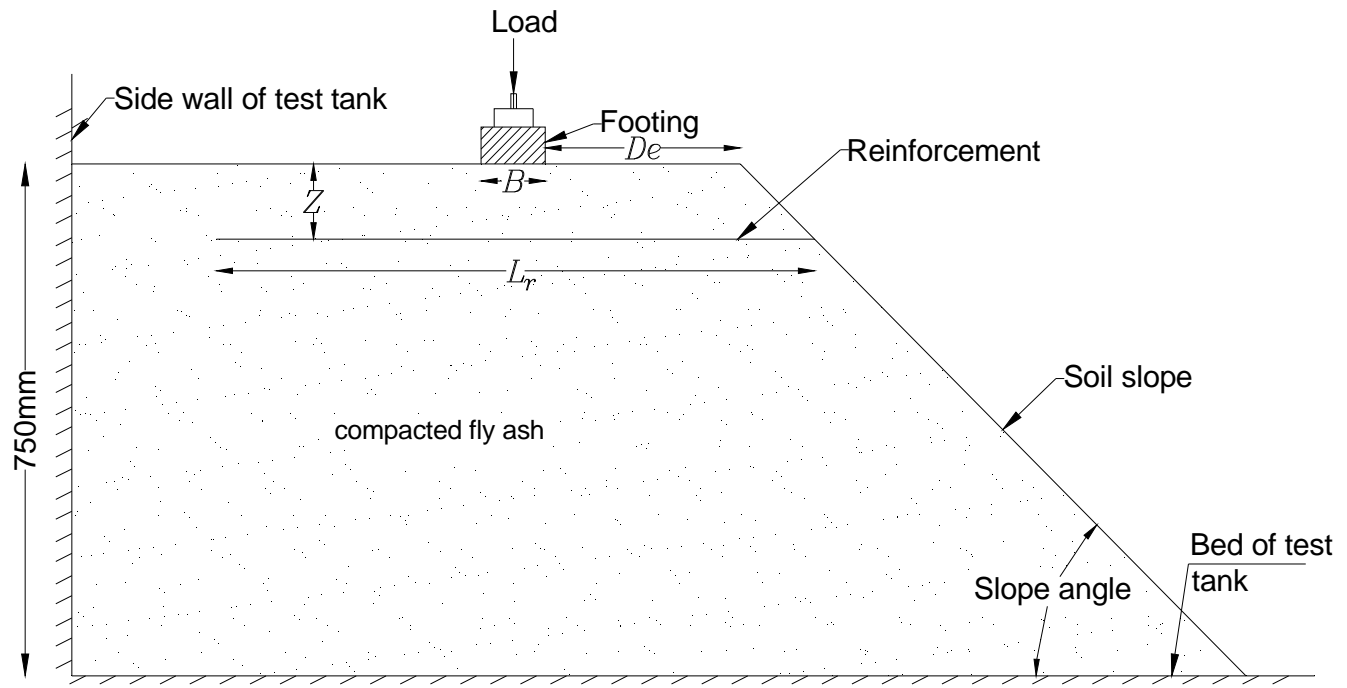

Fig. 1 Schematic view of test configuration.

Table 2 Parameters used in Numerical analysis.

\begin{tabular}{|c|c|c|c|c|}
\hline Parameters & Fly ash & \multicolumn{2}{|c|}{ Footing (Teak wood) } & Geogrid \\
\hline$e_{\text {init },} c_{k,} v$ & $0.500,1 E 015,0.380$ & $v$ & 0.20 & 0.00 \\
\hline$E_{\text {ref }}\left[\mathrm{kN} / \mathrm{m}^{2}\right]$ & 14000.000 & $E A[\mathrm{kN} / \mathrm{m}]$ & $1.092 E 08$ & 4.00 \\
\hline$G_{\text {ref }}\left[\mathrm{kN} / \mathrm{m}^{2}\right]$ & 5072.653 & $E I[\mathrm{kNm} / \mathrm{m}]$ & 445.89 & \\
\hline$E_{\text {oed }}\left[\mathrm{kN} / \mathrm{m}^{2}\right]$ & 26199.652 & $w[\mathrm{kN} / \mathrm{m} / \mathrm{m}]$ & 0.00 & \\
\hline$c_{\text {ref }}\left[\mathrm{kN} / \mathrm{m}^{2}\right]$ & 20.00 & $M_{p}[\mathrm{kNm} / \mathrm{m}]$ & $1 E 15$ & \\
\hline$\varphi\left[{ }^{\circ}\right], \psi\left[{ }^{\circ}\right]$ & $14,0.0$ & $N_{p}[\mathrm{kN} / \mathrm{m}]$ & $1 E 15$ & \\
\hline$E_{\text {inc }}\left[\mathrm{kN} / \mathrm{m}^{2} / \mathrm{m}\right]$ & 0.00 & & & \\
\hline$c_{\text {increment }}\left[\mathrm{kN} / \mathrm{m}^{2} / \mathrm{m}\right]$ & 0.00 & & & \\
\hline$y_{\text {ref }}[\mathrm{m}], T_{\text {str. }}\left[\mathrm{kN} / \mathrm{m}^{2}\right]$, & 0.00 & & & \\
\hline$R_{\text {inter. }}$ & 1.00 & & & \\
\hline
\end{tabular}

$e_{\text {init }}$ :Initial void ratio, $c_{k}$ :Change in permeability, $v$ :Poisson's ratio, $E_{\text {ref: }}$ Young's modulus, $G_{r e f}$ Shear modulus, $E_{\text {oed }}$ :Oedometer modulus, $c_{r e f}$ :Cohesion, $\psi$ : Dilatancy angle, $E_{\text {inc }}$ : Increase of stiffness, $C_{i n c}$ : Increase of cohesion, $R_{\text {inter }}:$ Strength reduction factor, $E I$ :Flexural rigidity, $w$ :Weight, $M_{p}$ :Maximum bending moment, $N_{p}$ :Axial force

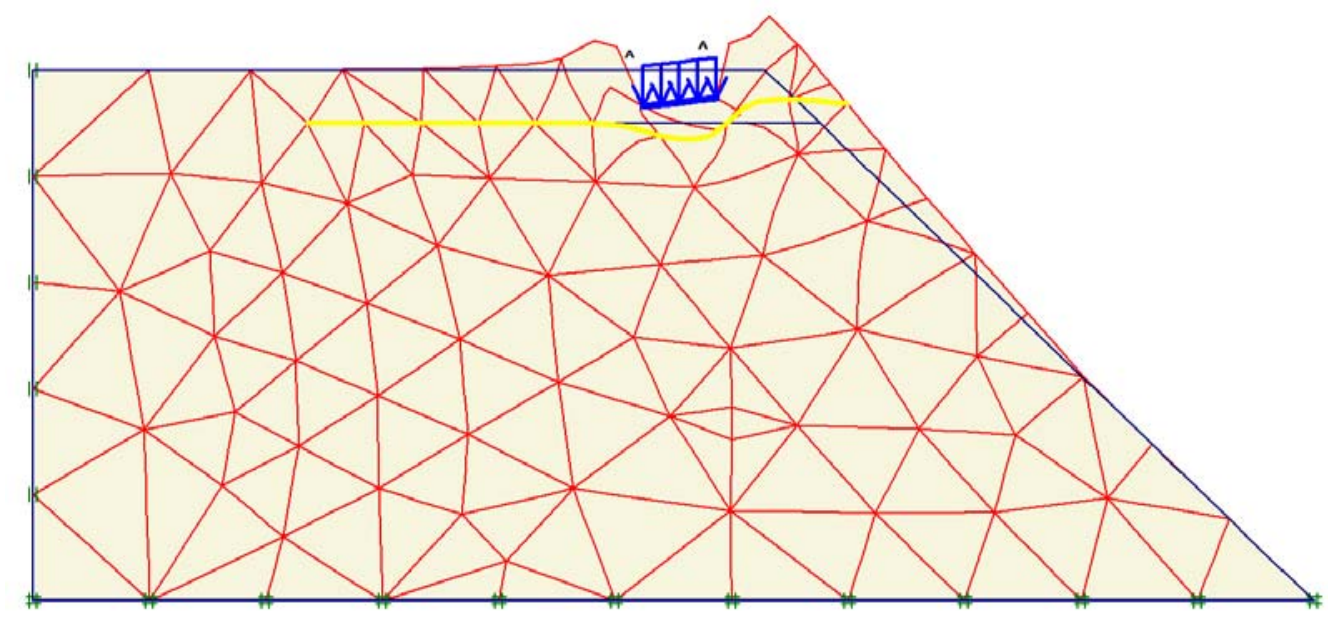

Fig. 2 Deformed mesh drawn from PLAXIS. 


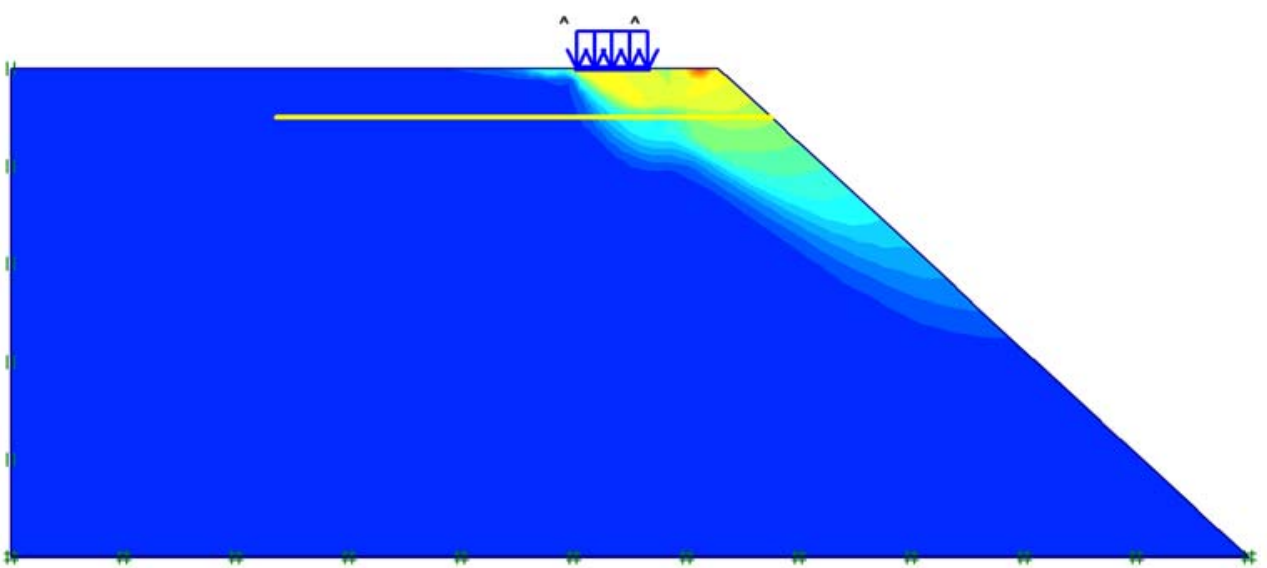

Fig. 3 Total displacement drawn from PLAXIS.

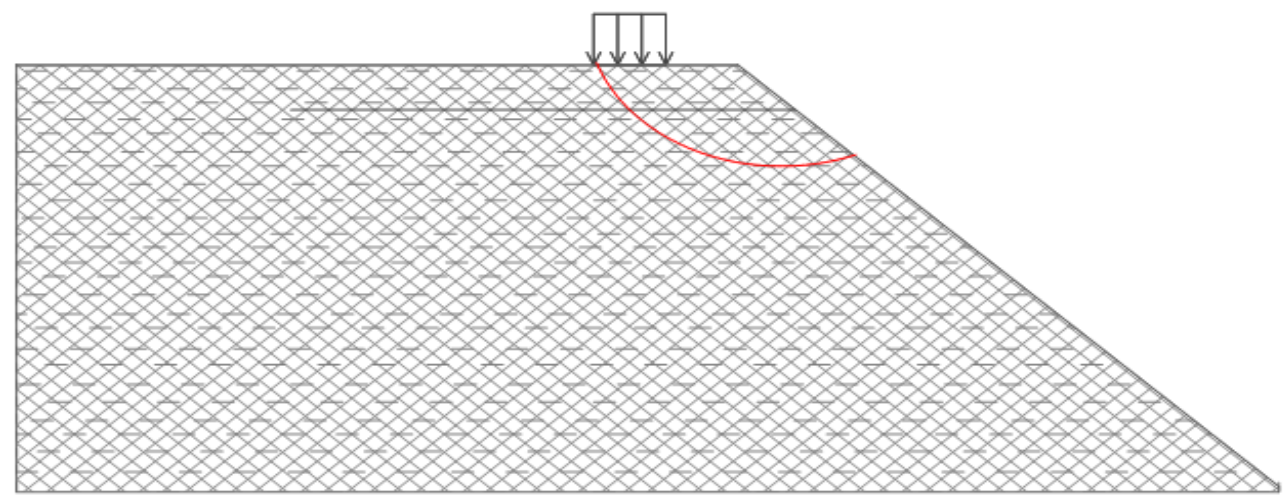

Fig. 4 Typical failure surface drawn from GEO5.

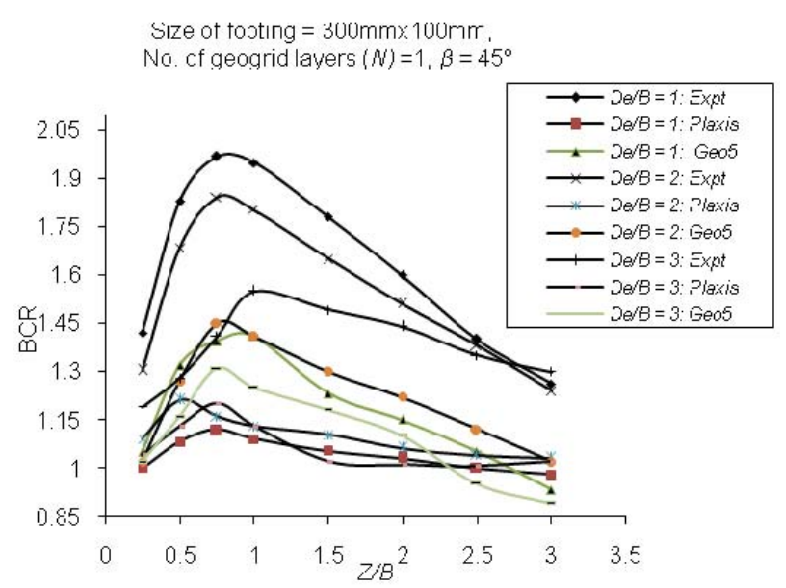

Fig. 5 Comparison of experimental and numerical results at different edge distance $\left(\beta=45^{\circ}\right)$.

results in spreading of footing load into a wider area beneath the reinforced zone, which is formed by a relatively rigid region of soil and reinforcement directly underneath the loaded area. This deep footing effect leads to an improved load carrying capacity of the footing however when geogrid is placed too close

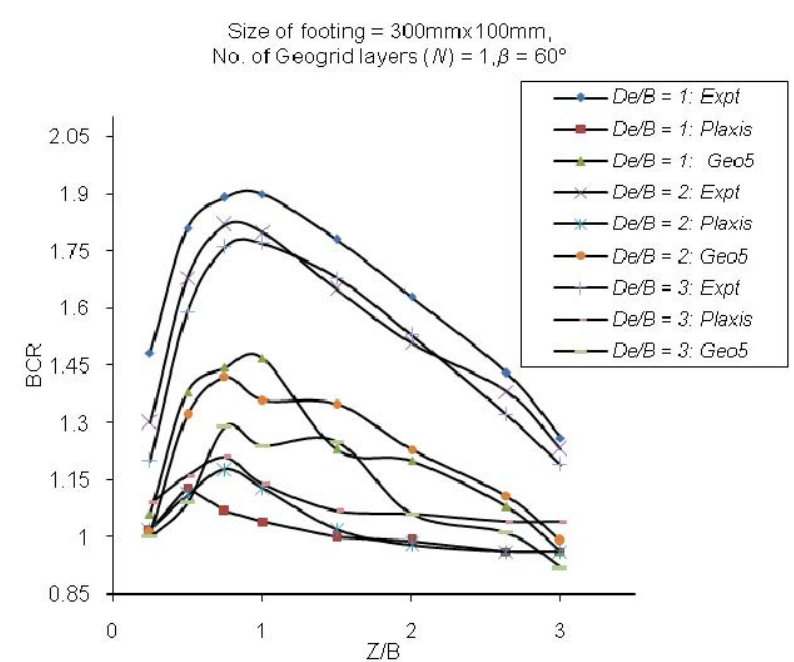

Fig. 6 Comparison of experimental and numerical results at different edge distance $\left(\beta=60^{\circ}\right)$.

to the footing $(Z / B<0.5)$ the overburden pressure on geogrid layer is inadequate in offering necessary anchorage resistance to the geogrid against pullout force. But for $Z / B=0.5-1.0$, the reinforcement enables much better load distribution over a larger area below 
the reinforced zone and a more adequate anchorage resistance can be mobilized under higher overburden pressure. This better load transfer mechanism results in optimum utilization of tensile strength of reinforcement. On the other hand, when $Z / B$ is greater than 1.0, the plastic failure zone does not extend below the reinforcement layer. The shear failure of soil takes place above the reinforcement layer thus rendering it ineffective. From the results of the investigation, though not reported pictorially here due to space limitation, it was found that for any given embedment depth and slope angle, the load carrying capacity of footing increases with increasing edge distance. Again for any given edge distance and embedment ratio, load carrying capacity decreases with increasing slope angle, which in the present experimental and numerical investigations was increased from 45 to 60 degrees for all the cases of unreinforced as well as reinforced slopes.

\section{Conclusions}

The bearing capacity behaviour of a strip footing resting on the top of a reinforced fly ash slope was investigated experimentally and numerically. The following conclusions may be drawn from the present study.

Fly ash can be successfully used as an embankment fill material.

Insertion of a geogrid reinforcement layer at a suitable location within the slope fill considerably improves the load carrying capacity of footings located on such slopes.

The location of the single geogrid layer at a depth of 0.5 to 1.0 times the footing width improves the load carrying capacity significantly.

The load carrying capacity of footing increases with an increase in edge distance and decreases with the increasing slope angle.

\section{References}

[1] A. Selvadurai and C. Gnanendran, An experimental study of a footing located on a sloped fill: Influence of a soil reinforcement layer, Canadian Geotechnical Journal 26 (3) (1989) 467-473.

[2] C. Huang, F. Tatsuoka and Y. Sato, Failure mechanism of reinforced sand slopes loaded with footing, Soil and Foundation 24 (2) (1994) 27-40.

[3] K. M. Lee and V. R. Manjunath, Experimental and numerical studies of geosynthetic reinforced sand slopes loaded with footing, Canadian Geotechnical Journal 37 (2000) 828-842.

[4] C. Yoo, Laboratory investigation of bearing capacity behavior of strip footing on geogrid reinforced sand slope, Geotextiles and Geomembranes 19 (2001) 279-298.

[5] M. EI Sawwaf, Behaviour of strip footing on geogrid reinforced sand over a soft clay slope, Geotextiles and Geomembranes 25 (2007) 50-60.

[6] S. Alamshahi and N. Hataf, Bearing capacity of strip fotings on sand slopes reinforced with geogrid and grid anchors, Geotextiles and Geomembranes 27 (2009) 217-226.

[7] S. Mittal, M. Y. Shah and N. K. Verma, Experimental study of footing on reinforced earth slope, International Journal of Geotechnical Engineering 3 (2) (2009) 251-260.

[8] S. K. Shukla, N. Sivakugan and B. M. Das, A state of the art review of geosynthetic reinforced slopes, International Journal of Geotechnical Engineering 5 (1) (2011) 17-32.

[9] A. K. Choudhary, J. N. Jha and K. S. Gill, Laboratory investigation of bearing capacity behavior of strip footing on reinforced fly ash slope, Geotextiles and Geomembranes 28 (4) (2010) 393-402.

[10] A. K. Choudhary and B. P. Verma, Behavior of footing on reinforced sloped fill, in: Proceedings of International Conference on Landmarks in Earth Reinforcement, Japan, 2001, pp. 535-539.

[11] J. N. Jha, A. K. Choudhary and K. S. Gill, Stability of strip footing on reinforced fly ash slope, in: Proceeding of 6th International Congress on Environmental Geotechnics, 2010, pp. 1160-1165.

[12] M. Datta, Design aspects of landfills, slurry ponds and waste dumps- some case studies from India, in: Proceeding of 6th International Congress on Environmental Geotechnics, 2010, pp. 40-51. 